\title{
Incidence of toxoplasmosis in women at a London hospital
}

\author{
C. F. RUOSS AND G. L. BOURNE
}

From the Department of Gynaecology, St. Bartholomew's Hospital, London

SYNOPSIS Toxoplasmosis is an infection, congenital or acquired, caused by Toxoplasma gondii. A pilot study using toxoplasmin skin antigen was undertaken to establish the incidence of the infection in the London area as a preliminary to a larger study of the effects of the infection upon pregnancy, the foetus, and the newborn infant.

\section{DESIGN OF THE EXPERIMENT AND RESULTS}

An intradermal skin test was employed using an antigen prepared by a technique similar to that described by Frenkel (1948). The peritoneal exudate was collected from mice infected with Toxoplasma gondii and the organisms were inactivated by repeated freeze-thaw cycles. The antigen was finally resuspended in an isotonic sodium chloride solution containing $0.25 \%$ phenol. A control was prepared by grinding mouse spleen into solution and subjecting it to a similar process.

Of the antigen, $0 \cdot 1 \% \mathrm{ml}$ was given into the left forearm and $0.1 \mathrm{ml}$ of control into the opposite forearm of 1,000 consecutive patients attending the Obstetric Department. The results were assessed at 24 and 48 hours and an area of induration or erythema greater than $7 \mathrm{~mm}$ in diameter was interpreted as a positive result, indicating a previous infection with Toxoplasma gondii.

A comparison between the results of the skin test and the Sabin-Feldman dye test was obtained by taking serum from the first 120 patients. The results were identical in $116(97 \%)$ patients. In the remaining four $(3 \%)$ the dye test was positive, while the skin test remained negative. There were no false positive results. Equivocal results were most unusual as there was rarely any noticeable reaction in the patients with negative results. No correlation could be established between the size of the positive skin reaction and the dye test titre. No patient showed any untoward reaction as a result of the skin test other than a well localized inflammatory response denoting a positive result which lasted usually from two to four days.

Received for publication 16 December 1968.
The skin test was found to take from 18 to 30 weeks to become positive after a recently acquired infection with Toxoplasma gondii. The criteria used for identification of such an infection was the change from a negative Sabin-Feldman dye test result to a positive result at a titre of at least 1 in 1,024 . The importance of this observation, together with the fact that no false positive skin tests were obtained, is that the presence of a high titre of dye test antibodies in association with a negative skin test indicates that the infection has been recently acquired. The skin test, therefore, becomes of value in a diagnostic capacity as well as being an important epidemiological tool.

A progressive increase occurs with age (Table I) amounting to between 0.75 and $1 \%$ increase per annum, which correlates well with serological surveys in the United States of America (Feldman and Miller, 1956) and in the South Wales area (Fleck, 1963).

\section{TABLE I}

ANALYSIS OF POSITIVE RESULTS RELATED TO AGE

\begin{tabular}{ll}
$\begin{array}{l}\text { Age Incidence } \\
(y r)\end{array}$ & Percentage Positive \\
\hline $15-20$ & 15 \\
$21-25$ & 29 \\
$26-30$ & 36 \\
$31-35$ & 38 \\
$36-40$ & 30 \\
$41-45$ & 42
\end{tabular}

An analysis of the countries of origin of the patient in this series (Table II) focuses on the fact that the infection is generally more common in warmer climates, as pointed out in American surveys (Feldman and Miller, 1956). A considerably higher 
TABLE II

ANALYSIS OF POSITIVE RESULTS RELATED TO PATIENT'S COUNTRY OF ORIGIN

\begin{tabular}{ll} 
Country of Origin & Percentage Positive \\
\hline England & 25 \\
Scotland & 38 \\
Wales & 37 \\
Ireland & 62 \\
Greece & 82 \\
Italy & 58 \\
Cyprus & 50 \\
West Africa & 84 \\
West Indies & 32
\end{tabular}

incidence was found in West African patients than in those from the West Indies. The incidence of the infection in the Irish was also noticeably higher than in the population of the rest of Great Britain.

It has been suggested that the infection might be contracted by contact with domestic or other animals. This possibility was investigated but no increase in incidence could be detected in those persons in frequent contact with animals, either in the course of their occupations or in the home. Neither could any greater incidence be found among those women who had lived the greater part of their lives in rural surroundings rather than in urban areas (Beattie, 1957), although this conclusion is rendered less valid by the varied origins of the population studied.

\section{COMMENT}

Variation in the incidence of toxoplasmosis in different areas is well recognized and is probably to be accounted for by the as yet unidentified mode of transmission of the acquired form of the disease. The incidence of the infection in the London area has not to our knowledge been reported previously and interesting differences within the British Isles are noted.
Although the reliability of the skin test has been questioned the degree of correlation with the $\overrightarrow{\vec{F}}$ cytoplasm-modifying test of Sabin and Feldman (1948) was $97 \%$. Beverley, Beattie, and Roseman $\frac{\bar{O}}{0}$ (1954) found a similar degree of correspondence, $\overline{\bar{c}}$ and Frenkel and Jacobs (1958) recommended it as $\mathbb{D}$ a reliable screening procedure. Feldman (1961), however, achieved poor correlation, and found that ${ }^{\infty}$ the skin test took at least a year to become positive $\vec{O}$ after an acute infection. We have found this time $\overrightarrow{.}$ interval to be somewhat shorter (18 to 30 weeks), $\omega$ but agree with him that a negative skin test need not imply that the patient has had no previous? experience with the parasite; such false negative skin? test results were of the order of $3 \%$ in our series. $\%$ A positive skin test is of value in excluding recent $\vec{b}$ infection (Remmington, Barnett, Meikel, and Lunde, 음 1962).

We should like to thank Dr Fleck, formerly of the Public Health Laboratory, Swansea, for performing the dye tests 3 and for his advice during the early stages of the survey. We are indebted to Eli Lilley \& Co., who provided the skin test antigen and control solution. We wish to thank $\vec{\theta}$ especially the Board of Governors of St Bartholomew's Hospital, who provided the financial support necessary to undertake this investigation, and also Mrs Booth of the Williamson Laboratory who was responsible for the laboratory techniques.

\section{REFERENCES}

Beattie, C. P. (1957). Trans. Roy. Soc. trop. Med. Hyg., 51, 96. Beverley, J. K. A., Beattie, C. P., and Roseman, C. (1954). J. Hyg. (Lond.), 52, 37.

Feldman, H. A. (1961). Surv. Ophthal., 6, 758.

- and Miller, L. T. (1956). Amer. J. Hyg., 64, 320.

Fleck, D. G. (1963). Epidemiology of Toxoplasmosis, J. Hyg. (Lond.), 61,61 .

Frenkel, J. K. (1948). Proc. Soc. exp. Biol. (N.Y.), 68, 634.

- and Jacobs, L. (1958). A.M.A. Arch. Ophthal., 59, 260.

Remmington, J. S., Barnett, C. G., Meikel, M., and Lunde, M. (1962). Arch. intern. Med., 110, 744.

Sabin, A. B., and Feldman, H. A. (1948). Science, 108, 660. 